\title{
Fitogeografia de Aldama (Asteraceae, Heliantheae) na América do Sul
} Phytogeography of Aldama (Asteraceae, Heliantheae) in South America

\author{
Mara Angelina Galvão Magenta ${ }^{1,3}$, Benoit Loeuille ${ }^{2}$ \& José Rubens Pirani ${ }^{2}$
}

\begin{abstract}
Resumo
Apresentamos um estudo fitogeográfico sobre Aldama (Asteraceae: Heliantheae) baseado em extenso trabalho de campo, dados da literatura e de herbários. As espécies foram enquadradas em Eco-regiões (Andina e Neotropical) e Domínios Fitogeográficos previamente estabelecidos para Poaceae (Campestre Tropical e Subtropical, Campestre Temperado e Campestre de Países Frios). A maioria pertence à Região Neotropical com grande representatividade no Domínio Campestre Tropical e Subtropical. Apenas $A$. revoluta chega à Sub-região Patagônica da Região Andina. Os limites oeste e norte de certas espécies encontram-se na Cordilheira dos Andes. Em contrapartida, as regiões de Yungas e Puna parecem constituir corredores conectando essas áreas andinas com a área centro-leste do gênero. No Brasil, as condições mais favoráveis à diversidade e densidade populacional de Aldama estão em áreas sob os climas megatérmicos (a grande maioria das exclusivamente brasileiras) ou mesotérmicos dos tipos Aw e Cwa de Köppen, que condicionam a paisagem dos cerrados. A maior expressividade de Aldama nesses ambientes abertos parece estar relacionada ao sistema subterrâneo espessado, que provê necessidades hídricas na seca e proteção contra fogo. São apresentados quatro padrões de distribuição de espécies: Exclusivas da Zona de Transição Sulamericana (10 spp.), Neotropicais-transicionais (oito spp.), Andino-transicionais (três spp.) e Neotropicais não transicionais (41 spp.).
\end{abstract}

Palavras-chave: Cerrado, distribuição geográfica, Região Andina, Região Neotropical, Viguiera.

\begin{abstract}
A phytogeographical study of Aldama (Asteraceae: Heliantheae) based on extensive field work, literature and herbaria data is presented here. Species were included in ecoregions (Andean and Neotropical) and phytogeographic dominions previously established for Poaceae (Tropical and Subtropical, Warm Temperate and Cold Temperate grasslands). The majority of species belong to the Neotropical Region, and there are also many in Tropical and Subtropical grasslands. Only A. revoluta reaches the Patagonian sub-region of the Andean Region. Western and northern limits of some species are in the Andes Mountains. In contrast, Yungas and Puna regions may be corridors, linking these areas with the east-central area of the genus. In Brazil, the most favorable conditions for diversity and population density of Aldama species occur in areas with megathermal climates (most of the exclusively Brazilian species) or mesothermal climates (seven species), the latter of Köppen types Aw and Cwa, which are related to Cerrado landscapes. The greatest expressivity of Aldama in these open habitats seems to be linked to the thick underground system, which provides water needs during the dry season and fire protection. Four patterns are presented: Exclusive to the South American Transition Zone (10 spp.), Neotropical-transitional (eight spp.), Andean transitional (three spp.) and Neotropical nontransitional (41 spp).
\end{abstract}

Key words: Cerrado, geographic distribution, Andean Region, Neotropical Region, Viguiera.

\footnotetext{
${ }^{1}$ Universidade Santa Cecília, Lab. Pesquisas Costeiras, R. Dr. Cesário Mota 8, lab. 82A, Boqueirão, 11045-040, Santos, SP, Brasil.

${ }^{2}$ Universidade de São Paulo, Inst. Biociências, R. do Matão 277, 05508-090, São Paulo, SP, Brasil.

${ }^{3}$ Autor para correspondência: maramagenta@unisanta.br
} 


\section{Introdução}

Até 2011, Aldama La Llave compreendia somente duas espécies distribuídas do México até o norte da América do Sul. Com a transferência, baseada em resultados de filogenia molecular (Schilling \& Panero 2011), das espécies sulamericanas de Viguiera Kunth sensu Blake (1918) para esse gênero, o número de espécies foi elevado para cerca de 120 espécies (Schilling \& Panero 2011; Magenta \& Pirani 2014). Nesta circunscrição, Aldama é um gênero americano, encontrado no sudoeste da América do Norte e México, e na América do Sul (Schilling \& Panero 2011), que ocorre predominantemente em regiões montanhosas e/ou abertas. Seus representantes são ervas geralmente perenes, com sistema subterrâneo espessado, sinflorescências com paracládios quase sempre alternos, cipselas simétricas ou levemente assimétricas, ligeiramente compressas, com pápus biaristado e escamas decíduas ou persistentes entre as aristas. Na América do Sul, o gênero possui entre 56 e 59 espécies, das quais 35 ocorrem no Brasil (Magenta \& Pirani 2014) e algo como 43\% são exclusivas do país.

Os aspectos biogeográficos do gênero são pouco estudados e foram abordados apenas superficialmente na literatura. A análise de sítios de restrição de DNA plastidial (Schilling \& Panero 1996) e das sequências de DNA ribossomal (ITS, ETS) (Schilling \& Panero 2002, 2011) apontou que várias das linhagens de Helianthineae que divergiram cedo ocupam atualmente a região do México. Uma das interpretações desse padrão sugere uma possível origem mexicana da subtribo, e com ocupação posterior da América do Sul (Schilling \& Panero 1996, 2002, 2011).

No presente trabalho apresentamos uma análise fitogeográfica, buscando detectar os padrões de distribuição de Aldama na América do Sul, de acordo com os critérios de Morrone (1999, 2001, 2004a, 2004b, 2006, 2014a, 2014b, 2015). O autor propôs a distinção de duas grandes regiões biogeográficas (Neotropical e Andina) para a América do Sul (Fig. 1) e reconhece uma zona de transição (Zona de Transição Sul-americana), que contempla parte das duas regiões reconhecidas.

Com essa análise, pretendemos prover um panorama biogeográfico abrangente de um gênero de Asteraceae rico em espécies na região Neotropical, especialmente no Brasil, que possibilite avanços em hipóteses de diversificação do grupo e forneça dados para auxiliar sua conservação biológica.

\section{Material e Métodos}

Baseamos a análise da distribuição geográfica de Aldama em dados de literatura (e.g., Beltrán et al. 2006; Blake 1918; Cavieres et al. 2001; Robinson \& Moore 2004), exploração a campo, com ênfase das espécies do Brasil (24 expedições, sendo uma aos Andes Chilenos e as demais cobrindo grandes áreas de oito estados brasileiros) e de coleções dos seguintes herbários: A, BHCB, BM, BOTU, BR, C, CEN, CESJ, CETEC, CGMS, COR, CPAP, CTES, E, ESA, FUEL, GH, HAS, HASU, HEPH, HRB, HRCB, HUCS, HUEFS, HUEPG, HUFU, IBGE, ICN, IPA, K, LP, LPB, M, MA, MBM, MPUC, NY, P, PACA, PEL, R, RB, S, SGO, SMDB, SP, SPF, SPFR, SPSF, UB, UEC, UFG, UFLA, UFMT, UPF, US, VEN (Thiers, continuamente atualizado). A relação completa de material examinado coletado no Brasil pode ser encontrada em Magenta (2006); a listagem dos demais materiais pode ser solicitada à primeira autora.

Estabelecemos os padrões fitogeográficos de Aldama na América do Sul, considerando a distribuição das espécies nas Eco-regiões Andina e Neotropical e na Zona de Transição da América do Sul, segundo classificação de Morrone (2014b, 2015).

Diante da flagrante restrição da distribuição das espécies estudadas a habitats abertos, fizemos também uma análise correlacionada com a classificação de Burkart (1975) para Poaceae, que estabelece três Domínios sul-americanos, de acordo com exigências de temperatura das gramíneas (Domínio Campestre Tropical e Subtropical, constituído por grupos megatérmicos, Domínio Campestre Temperado, formado por grupos mesotérmicos e Domínio Campestre de Países Frios, com grupos microtérmicos).

Para elaboração dos mapas, utilizamos o software QGIS 2.6 (2014). O Mapa de distribuição de Aldama nas Regiões Andina e Neotropical e na Zona de Transição Sul-americana elaborado usando o "shapefile" de Löwenberg-Neto 2014, 2015, criado a partir dos mapas originais de Morrone (2014b, 2015).

\section{Resultados e Discussão}

Distribuição geográfica e fatores relacionados

O mapeamento da distribuição geográfica de Aldama mostra uma distribuição claramente disjunta entre o conjunto das espécies sulamericanas e o das do Hemisfério Norte, sem 


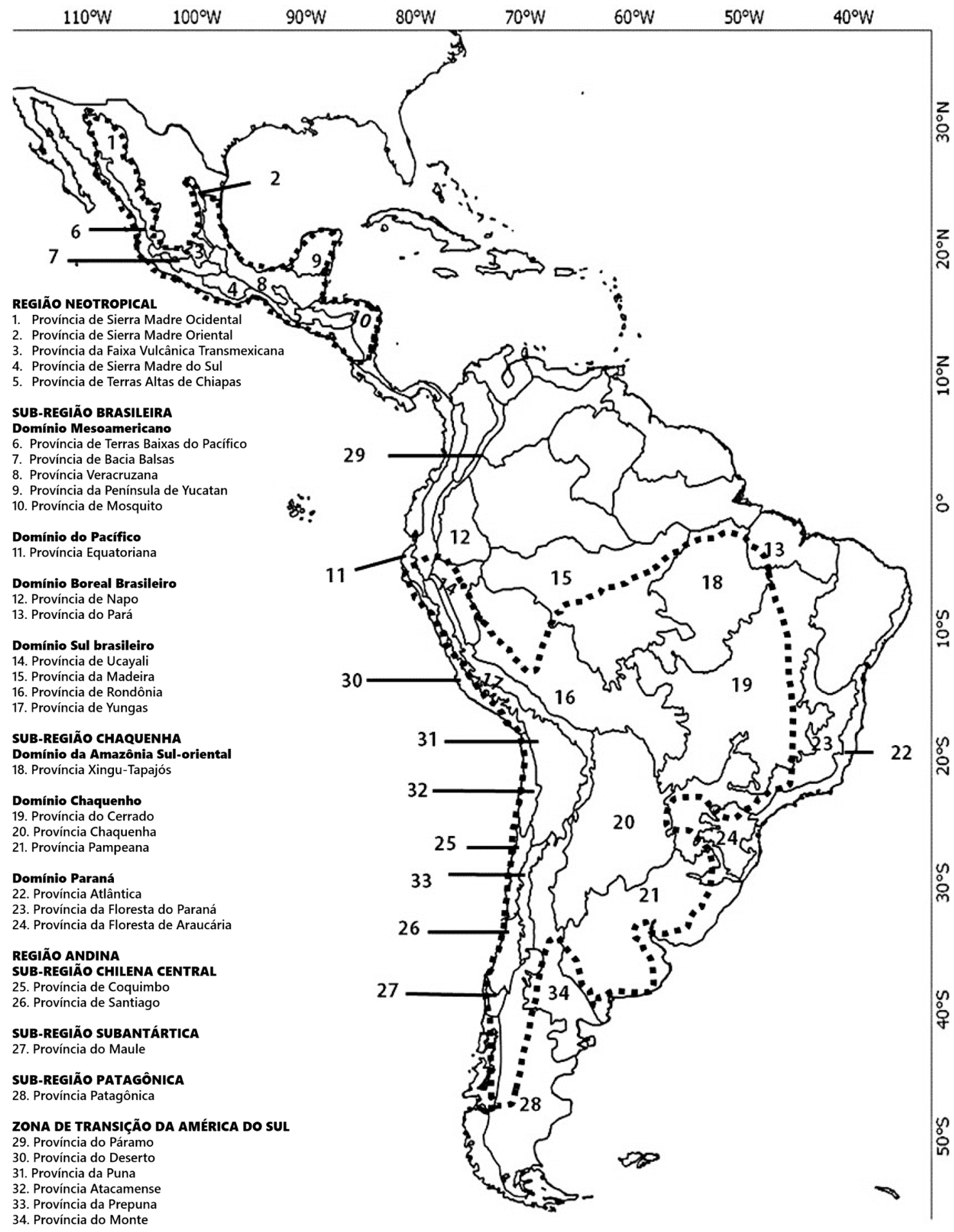

Figura 1 - Distribuição de Aldama La Lave (linha pontilhada) nas Sub-regiões e Províncias das Regiões Neotropical e Andina e da Zona de Transição Sul-americana (modificado de Löwenberg-Neto 2014, 2015 e Morrone 2015). Figure 1 - Distribution of Aldama La Lave (dotted line) in Sub-regions and provinces of Neotropical and Andean Regions and of the South American Transition Zone (modified from Löwenberg-Neto 2014, 2015 and Morrone 2015). 
registro de ocorrência de qualquer espécie do gênero na área que vai da Costa Rica à Colômbia (Fig. 1). Nenhuma espécie ocorre em ambas as subáreas do gênero, e, portanto não há congruência em nível específico com qualquer dos padrões peri-amazônicos descritos para espécies de outros grupos de plantas vasculares por Granville (1992). No entanto, as análises filogenéticas baseadas em dados morfológicos de Aldama da América do Sul (sob Viguiera s.1.), feitas por Magenta (2006), indicam uma estreita relação entre as plantas andinas e as mexicanas pertencentes ao subgênero Amphilepis S.F. Blake, das seções Leighia e Hypargyrea e algumas da série Grammatoglossae de Viguiera (senso Blake 1918). São plantas com sinflorescências apresentando paracládios ebracteolados ou com 1-2 bractéolas, brácteas involucrais hirsutas a híspidas ou raramente estrigilosas. Efetivamente, nas análises filogenéticas combinando dados moleculares de ITS e ETS realizadas por Schilling \& Panero (2011) espécies sul-americanas e espécies mexicanas dos grupos de Viguiera s.l. citados acima, juntamente com Aldama, emergiram no mesmo grupo, exceto duas espécies mexicanas de Aldama (A. canescens e $A$. cordifolia) que apareceram em outro clado, junto a espécies de Pappolobus, Heiseria, Scalesia e Syncretocarpus.

As disjunções florísticas entre as Américas têm sido alvo de várias investigações e uma rota de migração entre as Américas do Norte e do Sul é reconhecida (Raven 1974; Gentry 1978; IturraldeVinent 1999). Conforme as evidências geológicas e biológicas se acumulam (e.g., Stehli \& Webb 1985) reforçam que as similaridades florísticas entre as essas partes do Continente podem ser explicadas considerando-se a América central como uma conexão (Delgadillo 1992, 1993; Lopez et al. 2006)

Luebert \& Weigent (2014) ressaltam que a localização geográfica dos Andes no continente sul-americano deu origem a várias propostas de que a cordilheira atua como um corredor, promovendo o intercâmbio Norte-Sul de elementos bióticos e age como uma barreira, gerando vicariância, tanto no sentido Leste-Oeste como interna, podendo promover especiação, pela disponibilização de ambientes de alta altitude durante a sua formação. A história de Aldama deve estar envolvida nesse cenário, mas os dados atuais, sem um cronograma (filogenia com datação) do grupo, não permitem qualquer hipótese robusta sobre o papel relativo de eventos de dispersão, vicariância ou extinção na sua trajetória.
Em relação ao clima, correlacionamos a distribuição de Aldama na América do Sul aos grupos de gramíneas estabelecidos por Burkart (1975), que reconheceu três grupos de espécies:

Grupos megatérmicos: constituídos por plantas de áreas equatoriais e tropicais com temperatura média anual de $20^{\circ} \mathrm{C}$ ou mais e $15^{\circ} \mathrm{C}$ ou mais de temperatura invernal; na América do Sul, tais condições são encontradas nos planaltos e serras baixas, entre cerca de $13^{\circ} \mathrm{N}$ e $28^{\circ} \mathrm{S}$, e também nas partes baixas (até $1500 \mathrm{~m}$ ) da Cordilheira dos Andes. Para o autor, esses grupos constituem o Domínio Campestre Tropical e Subtropical, com vegetação de cerrado e dominado por plantas megatérmicas, abrange os Llanos de Orinoco, na Colômbia e Venezuela, os Campos e Cerrados do Brasil Central, as planícies alagáveis como o Pantanal brasileiro, as partes ao Norte dos Campos Sulinos do Brasil e as formações campestres tropicais e subtropicais do leste dos Andes, que se estendem numa estreita extensão, até o sopé dos Andes, da Venezuela, Colômbia à Bolívia e noroeste da Argentina. As 39 espécies de Aldama inseridas neste grupo estão marcadas na Tabela 1. Ressaltamos que 13 delas não são exclusivamente megatérmicas.

Grupos mesotérmicos: englobam as plantas que requerem temperaturas médias anuais entre 10 e $20^{\circ} \mathrm{C}$ e invernais de 5 a $15^{\circ} \mathrm{C}$; essas condições prevalecem nas regiões temperadas da América do Sul (Argentina central, Chile Uruguai e extremo Sul do Brasil), entre 28 e $40^{\circ} \mathrm{S}$, e nos Andes entre 1500 e $3000 \mathrm{~m}$ de altitude. $O$ fator temperatura é menos importante e as condições hídricas controlam as fases da vegetação; assim, há um gradiente de leste a oeste, de condições úmidas a xéricas, com pampas e campos no Uruguai, Brasil e, na Argentina, em Entre Rios e Corrientes, e vegetação xerófila de Monte, a oeste da Argentina, com uma variada composição florística intermediária (Zucol 2000). Para Burkart, formam o Domínio Campestre Temperado. As 34 espécies de Aldama inseridas neste grupo estão assinaladas na Tabela 1. Ressaltamos que quase $65 \%$ (22 espécies) não são exclusivamente mesotérmicas.

Grupos microtérmicos: aqui se enquadram as plantas de áreas com climas temperados frios ou frios, com menos de $10^{\circ} \mathrm{C}$ de temperatura média anual e menos de $5^{\circ} \mathrm{C}$ de temperatura média invernal. Tais condições se apresentam em elevadas latitudes ou em altitudes acima de $3500 \mathrm{~m}$ ao longo da Cordilheira dos Andes. Esses grupos formam o Domínio Campestre de Países 
Tabela 1 - Distribuição das espécies da América do Sul em eco-regiões, segundo a divisão de Morrone (2014b, 2015). Abreviatura do nome das províncias biogeográficas. Par = Páramo, Yun = Yungas, Cha = Chaquenha, Pam $=$ Pampeana, Cer $=$ Cerrado, Atl $=$ Floresta Atlântica, FlP $=$ Floresta do Paraná, Ara = Floresta de Araucária, Des $=$ Deserto, Pun $=$ Puna, Ata $=$ Atacama, Pre $=$ Prepuna, Mon = Monte, Coq $=$ Coquimbo, San $=$ Santiago, Mau= Maule, Pat $=$ Patagônica Grupos climáticos: $\operatorname{meg}=$ megatérmica, mes = mesotérmica, mic = microtérmica. Domínios: $1=$ Campestre Tropical e Subtropical, 2 = Campestre Temperado, 3 = Campestre de Países Frios.

Table 1 - Distribution of South American species of Aldama in ecoregions according to Morrone (2014b, 2015). Abbreviation of names for biogeographical provinces. $\mathrm{Par}=$ Paramo, Yun $=$ Yungas, $\mathrm{Cha}=$ Chaco, $\mathrm{Pam}=$ Pampean, $\mathrm{Cer}=\mathrm{Cerrado}, \mathrm{Atl}=\mathrm{Atlantic} \mathrm{Forest,} \mathrm{FlP}=$ Parana Forest, Ara $=$ Araucaria Forest, Des $=$ Desert, Pun $=$ Puna, Ata $=$ Atacama, Pre $=$ Prepuna, Mon $=$ Monte, Coq $=$ Coquimbo, San $=$ Santiago, $\mathrm{Mau}=$ Maule, $\mathrm{Pat}=$ Patagonian . Climatic groups: $\mathrm{meg}=$ megathermic, mes $=$ mesothermic, mic $=$ microthermic. Domains: $1=$ Tropical and Subtropical grasslands, $2=$ Temperate grasslands, $3=$ Cold Countries graslands.

\begin{tabular}{|c|c|c|c|c|c|c|c|c|c|c|c|c|}
\hline \multirow{4}{*}{$\begin{array}{l}\text { Subregião / Zona de Transição } \\
\text { Espécies / Província }\end{array}$} & & & & & & & & \multicolumn{3}{|c|}{ Região Andina } & \multirow{4}{*}{ - } & \multirow{4}{*}{ 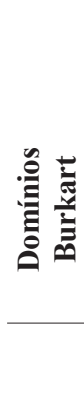 } \\
\hline & \multicolumn{9}{|c|}{ Região Neotropical } & \multirow{3}{*}{ 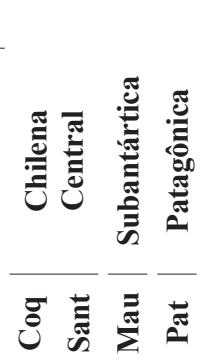 } & & \\
\hline & \multicolumn{3}{|l|}{ 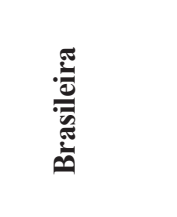 } & \multicolumn{4}{|c|}{ 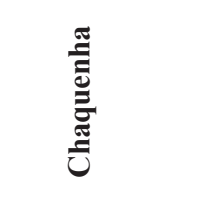 } & \multicolumn{2}{|r|}{ 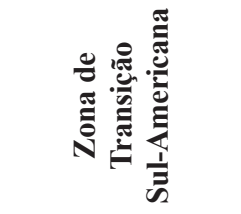 } & & & \\
\hline & $\stackrel{\bar{\pi}}{2}$ & $\frac{\pi}{0}$ & E & $\dot{\bar{j}}$ & $E$ & $\hat{\bar{I}}$ & $\stackrel{T}{4}$ & $\stackrel{\Xi}{0}$ & 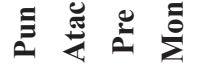 & & & \\
\hline $\begin{array}{l}\text { Aldama adenotricha (S.F. Blake) } \\
\text { E.E. Schill. \& Panero }\end{array}$ & & & & & & & & $*$ & & * & $\begin{array}{l}\text { meg; } \\
\text { mes; } \\
\text { mic }\end{array}$ & 2 \\
\hline $\begin{array}{l}\text { Aldama amphichlora (S.F. Blake) } \\
\text { E.E. Schill. \& Panero }\end{array}$ & & & & & & * & & & & & mes & 2 \\
\hline $\begin{array}{l}\text { Aldama anchusifolia (DC.) E.E. } \\
\text { Schill. \& Panero }\end{array}$ & & & $*$ & & * & * & * & & & & mes & 2 \\
\hline $\begin{array}{l}\text { Aldama arenaria (Baker) E.E. } \\
\text { Schill. \& Panero }\end{array}$ & & & & * & & & & & & & $\begin{array}{l}\text { meg; } \\
\text { mes }\end{array}$ & 1 \\
\hline $\begin{array}{l}\text { Aldama aspilioides (Baker) E.E. } \\
\text { Schill. \& Panero }\end{array}$ & & & & & & & * & & & & meg & 1 \\
\hline $\begin{array}{l}\text { Aldama atacamensis (Phil.) E.E. } \\
\text { Schill. \& Panero }\end{array}$ & & & & & & & & & * & & mes & 1 \\
\hline $\begin{array}{l}\text { Aldama australis (S.F. Blake) E.E. } \\
\text { Schill. \& Panero }\end{array}$ & * & $*$ & & & & & & & $*$ & & mes & $1 ; 3$ \\
\hline $\begin{array}{l}\text { Aldama bakeriana (S.F. Blake) E.E. } \\
\text { Schill. \& Panero }\end{array}$ & & & & * & & & & & & & $\begin{array}{l}\text { meg; } \\
\text { mes }\end{array}$ & 1 \\
\hline $\begin{array}{l}\text { Aldama bishopii (H.Rob.) E.E. } \\
\text { Schill. \& Panero }\end{array}$ & & & & & & & & & $*$ & & meg & 1 \\
\hline $\begin{array}{l}\text { Aldama bracteata (Gardner) E.E. } \\
\text { Schill. \& Panero }\end{array}$ & & & & * & & & & & & & meg & 1 \\
\hline $\begin{array}{l}\text { Aldama breviflosculosa (S.F. Blake) } \\
\text { E.E. Schill. \& Panero }\end{array}$ & & & * & & & & & & & & mes & 2 \\
\hline $\begin{array}{l}\text { Aldama brittonii (Hochr.) E.E. } \\
\text { Schill. \& Panero }\end{array}$ & * & & & & & & & $*$ & & & $\begin{array}{l}\text { meg; } \\
\text { mes; } \\
\text { mic }\end{array}$ & $1 ; 3$ \\
\hline $\begin{array}{l}\text { Aldama corumbensis (Malme) } \\
\text { Magenta \& Pirani }\end{array}$ & & & & * & & & & & & & meg & 1 \\
\hline
\end{tabular}




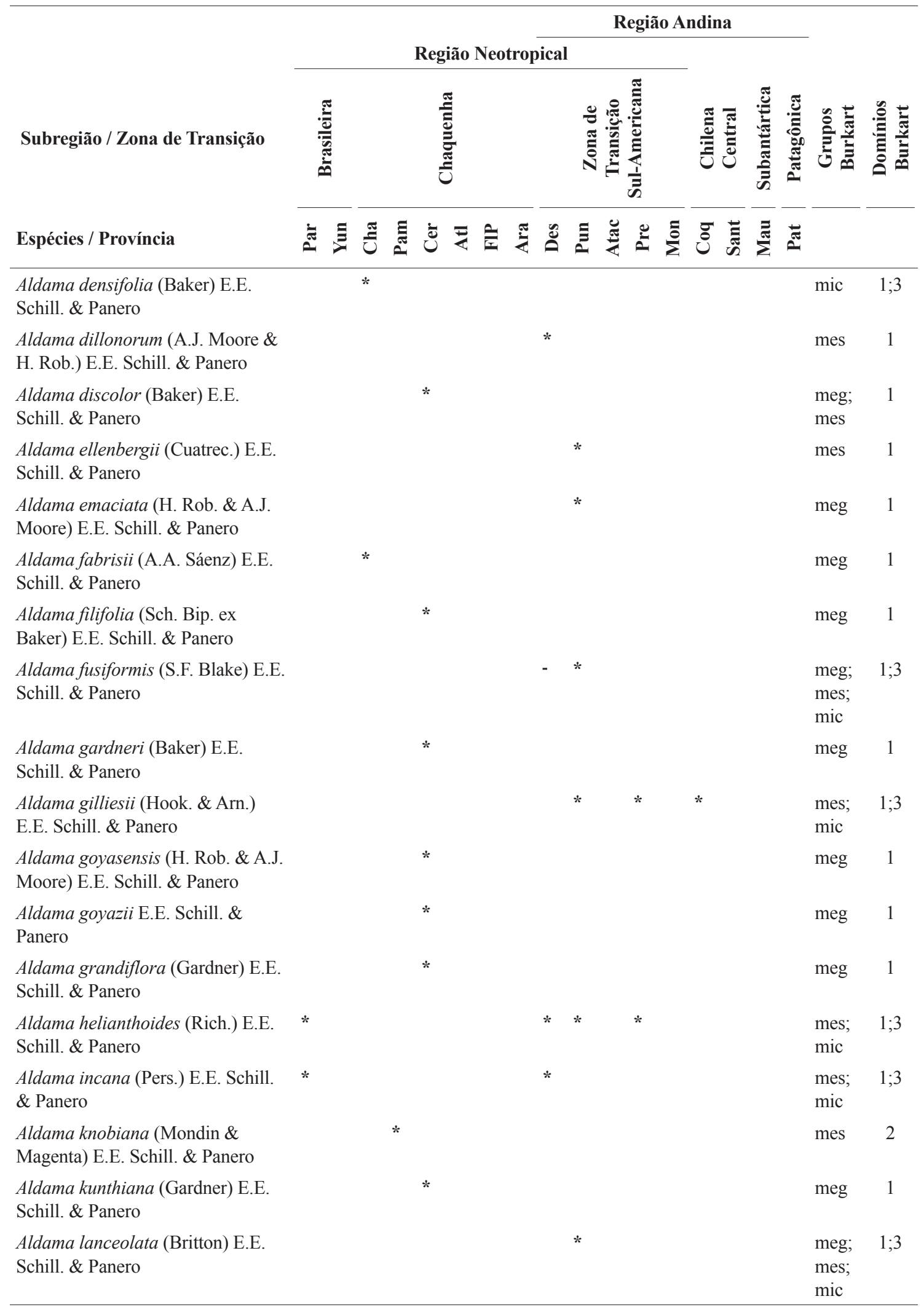




\begin{tabular}{|c|c|c|c|c|c|c|c|c|c|c|c|c|c|c|c|c|c|c|c|}
\hline \multirow{4}{*}{$\begin{array}{l}\text { Subregião / Zona de Transição } \\
\text { Espécies / Província }\end{array}$} & \multicolumn{17}{|c|}{ Região Andina } & \multirow{4}{*}{ 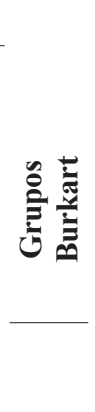 } & \multirow{4}{*}{ 象兽 } \\
\hline & \multicolumn{13}{|c|}{ Região Neotropical } & \multirow{2}{*}{\multicolumn{2}{|c|}{ نี }} & \multirow{3}{*}{ 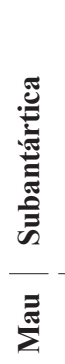 } & \multirow{3}{*}{ 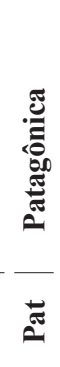 } & & \\
\hline & \multicolumn{2}{|c|}{ 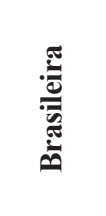 } & \multicolumn{6}{|c|}{ 胥 } & \multicolumn{5}{|c|}{ 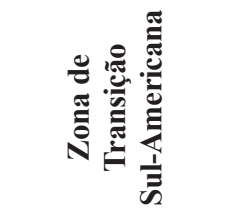 } & & & & & & \\
\hline & $\stackrel{\Xi}{=}$ & $\Xi$ & ฮี & $\stackrel{\Xi}{\Xi}$ & $\dot{\bar{\theta}}$ & $\bar{z}$ & $\hat{\bar{I}}$ & $\underset{4}{2}$ & $\stackrel{\tilde{\theta}}{0}$ & $\Xi$ & $\stackrel{\tilde{T}}{\gtrless}$ & $\stackrel{0}{2}$ & $\stackrel{\Xi}{\Sigma}$ & ن & 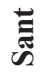 & & & & \\
\hline $\begin{array}{l}\text { Aldama laxicymosa (H. Rob. \& A.J. } \\
\text { Moore) E.E. Schill. \& Panero }\end{array}$ & & & & & $*$ & & & & & & & & & & & & & meg & 1 \\
\hline $\begin{array}{l}\text { Aldama linearifolia (Chodat) E.E. } \\
\text { Schill. \& Panero }\end{array}$ & & & & & * & & $*$ & & & & & & & & & & & meg & 1 \\
\hline $\begin{array}{l}\text { Aldama macbridei (S.F. Blake) E.E. } \\
\text { Schill. \&Panero }\end{array}$ & & & & & & & & & & & & & & & & & & mes & 1 \\
\hline $\begin{array}{l}\text { Aldama macrorhiza (Baker) E.E. } \\
\text { Schill. \& Panero }\end{array}$ & & & & & * & & $*$ & & & $*$ & & & & & & & & meg & 1 \\
\hline $\begin{array}{l}\text { Aldama media (S.F. Blake) E.E. } \\
\text { Schill. \& Panero }\end{array}$ & $*$ & & & & & & & & & & & & & & & & & $\begin{array}{l}\text { mes; } \\
\text { mic }\end{array}$ & $1 ; 3$ \\
\hline $\begin{array}{l}\text { Aldama megapotamica (Malme) } \\
\text { Magenta \& Pirani }\end{array}$ & & & & * & & & & * & & & & & & & & & & mes & 2 \\
\hline $\begin{array}{l}\text { Aldama meridionalis (Magenta) } \\
\text { E.E. Schill. \& Panero }\end{array}$ & & & & $*$ & & & & & & & & & & & & & & mes & 2 \\
\hline $\begin{array}{l}\text { Aldama mollis (Griseb.) E.E. Schill. } \\
\& \text { Panero }\end{array}$ & & & * & $*$ & & & & & & $*$ & & & $*$ & & & & & meg & 1 \\
\hline $\begin{array}{l}\text { Aldama nudibasillaris (S.F. Blake) } \\
\text { E.E. Schill. \& Panero }\end{array}$ & & & & & $*$ & & $*$ & & & & & & & & & & & $\begin{array}{l}\text { meg; } \\
\text { mes }\end{array}$ & 1 \\
\hline $\begin{array}{l}\text { Aldama nudicaulis (Baker) E.E. } \\
\text { Schill. \& Panero }\end{array}$ & & & & $*$ & & & & & & & & & & & & & & mes & 2 \\
\hline $\begin{array}{l}\text { Aldama oblongifolia (Gardner) E.E. } \\
\text { Schill. \& Panero }\end{array}$ & & & & & $*$ & & & & & & & & & & & & & meg & 1 \\
\hline $\begin{array}{l}\text { Aldama paranensis (Malme) } \\
\text { Magenta \& Pirani }\end{array}$ & & & & & & & & * & & & & & & & & & & meg & 1 \\
\hline $\begin{array}{l}\text { Aldama peruviana (A.Gray) E.E. } \\
\text { Schill. \& Panero }\end{array}$ & & & & & & & & & $*$ & & & & & & & & & $\begin{array}{l}\text { mes; } \\
\text { mic }\end{array}$ & $1 ; 3$ \\
\hline $\begin{array}{l}\text { Aldama pilicaulis (S.F. Blake) E.E. } \\
\text { Schill. \& Panero }\end{array}$ & & & & & $*$ & & $*$ & & & & & & & & & & & meg & 1 \\
\hline $\begin{array}{l}\text { Aldama pilosa (Baker) E.E. Schill. } \\
\& \text { Panero }\end{array}$ & & & & $*$ & & $*$ & $*$ & $*$ & & & & & & & & & & mes & 2 \\
\hline $\begin{array}{l}\text { Aldama retroflexa (S.F. Blake) E.E. } \\
\text { Schill. \& Panero }\end{array}$ & & & & & & & & & & $*$ & & & & & & & & $\begin{array}{l}\text { mes; } \\
\text { mic }\end{array}$ & $1 ; 3$ \\
\hline $\begin{array}{l}\text { Aldama revoluta (Meyen) E.E. } \\
\text { Schill. \& Panero }\end{array}$ & & & & & & & & & * & $*$ & $*$ & $*$ & $*$ & $*$ & $*$ & $*$ & * & $\begin{array}{l}\text { meg; } \\
\text { mes; } \\
\text { mic }\end{array}$ & $1 ; 2 ; 3$ \\
\hline $\begin{array}{l}\text { Aldama robusta (Gardner) E.E. } \\
\text { Schill. \& Panero }\end{array}$ & & & & & $*$ & & & & & & & & & & & & & meg & 1 \\
\hline $\begin{array}{l}\text { Aldama rubra (Magenta \& Pirani) } \\
\text { E.E. Schill. \& Panero }\end{array}$ & & & & & $*$ & & & & & & & & & & & & & meg & 1 \\
\hline
\end{tabular}




\begin{tabular}{|c|c|c|c|c|c|c|c|c|c|c|c|c|c|c|c|c|c|}
\hline \multirow{4}{*}{$\begin{array}{l}\text { Subregião / Zona de Transição } \\
\text { Espécies / Província }\end{array}$} & \multicolumn{15}{|c|}{ Região Andina } & & \multirow{4}{*}{ 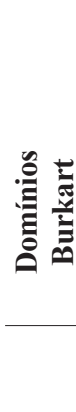 } \\
\hline & \multicolumn{12}{|c|}{ Região Neotropical } & \multirow[b]{2}{*}{ 氖苞 } & \multirow{3}{*}{ 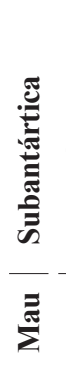 } & & & \\
\hline & \multicolumn{2}{|c|}{ : } & \multicolumn{6}{|c|}{ 胥 } & \multicolumn{4}{|c|}{ N } & & & & & \\
\hline & 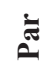 & $\Xi$ & $\stackrel{\Xi}{己}$ & $\stackrel{\Xi}{E}$ & ฮ் & $\bar{z}$ & $\hat{\bar{I}}$ & $\underset{3}{4}$ & $\stackrel{\mathscr{\Xi}}{0}$ & 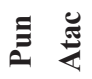 & $\stackrel{0}{2}$ & है & ¿ & & & & \\
\hline $\begin{array}{l}\text { Aldama santacatarinensis (H. } \\
\text { Rob. \& A.J. Moore) E.E. Schill. \& } \\
\text { Panero }\end{array}$ & & & & & & $*$ & $*$ & $*$ & & & & & & & & $\begin{array}{l}\text { meg; } \\
\text { mes }\end{array}$ & $1 ; 3$ \\
\hline $\begin{array}{l}\text { Aldama sodiroi (Hieron.) E.E. } \\
\text { Schill. \& Panero }\end{array}$ & $*$ & & & & & & & & & & & & & & & $\begin{array}{l}\text { mes; } \\
\text { mic }\end{array}$ & $1 ; 3$ \\
\hline $\begin{array}{l}\text { Aldama speciosa (Hassl.) E.E. } \\
\text { Schill. \& Panero }\end{array}$ & & & * & & & & & & & & & & & & & meg & 1 \\
\hline $\begin{array}{l}\text { Aldama squalida (S.Moore) E.E. } \\
\text { Schill. \& Panero }\end{array}$ & & & & & $*$ & & & & & & & & & & & meg & 1 \\
\hline $\begin{array}{l}\text { Aldama tenuifolia (Gardner) E.E. } \\
\text { Schill. \& Panero }\end{array}$ & & & & & $*$ & & & & & & & & & & & $\begin{array}{l}\text { meg; } \\
\text { mes }\end{array}$ & 1 \\
\hline $\begin{array}{l}\text { Aldama trichophylla (Dusén) } \\
\text { Magenta }\end{array}$ & & & & & & & $*$ & $*$ & & & & & & & & meg & 1 \\
\hline $\begin{array}{l}\text { Aldama truxillensis (Kunth) E.E. } \\
\text { Schill. \& Panero }\end{array}$ & & $*$ & & & & & & & * & & & & & & & $\begin{array}{l}\text { meg; } \\
\text { mes; } \\
\text { mic }\end{array}$ & $1 ; 2 ; 3$ \\
\hline $\begin{array}{l}\text { Aldama tuberosa (Griseb.) E.E. } \\
\text { Schill. \& Panero }\end{array}$ & & & $*$ & $*$ & $*$ & & & * & & & & & & & & $\begin{array}{l}\text { meg; } \\
\text { mes }\end{array}$ & 1 \\
\hline $\begin{array}{l}\text { Aldama tucumanensis (Hook. \& } \\
\text { Arn.) E.E. Schill. \& Panero }\end{array}$ & & & * & $*$ & & & & & & $*$ & * & & & & & $\begin{array}{l}\text { mes; } \\
\text { mic }\end{array}$ & 2 \\
\hline $\begin{array}{l}\text { Aldama veredensis (Magenta \& } \\
\text { Pirani) E.E. Schill. \& Panero }\end{array}$ & & & & & $*$ & & & & & & & & & & & meg & 1 \\
\hline $\begin{array}{l}\text { Aldama vernonioides (Baker) E.E. } \\
\text { Schill. \& Panero }\end{array}$ & & & & & $*$ & & & & & & & & & & & meg & 1 \\
\hline
\end{tabular}

Frios, que abarca os Páramos da Venezuela, Colômbia e Equador, as estepes andinas do Peru, Bolívia e noroeste da Argentina e as estepes da Patagônia. As 16 espécies de Aldama inseridas aqui estão assinaladas na Tabela 1. Ressaltamos apenas uma delas é exclusivamente microtérmica (A. densifolia).

Mais de $42 \%$ das espécies de Aldama da América do Sul e quase $63 \%$ das espécies do Brasil são exclusivamente megatérmicas. Apenas seis (cerca de 10\%) das espécies sul-americanas suportam grande amplitude térmica, ocorrendo em todos os Domínios de Burkart (1975).

Na Região Neotropical (Morrone 2014) está a maioria dos táxons Sul-americanos de Aldama, concentrados principalmente na Província do Cerrado, da Sub-região Chaquenha (Tab. 1).

Apenas três espécies chegam à porção da Região Andina que não inclui a Zona de Transição: A. adenotricha, $A$. gilliesiii e $A$. revoluta (Fig. 2c), esta última alcançando o limite sul (ca. $\left.38^{\circ} \mathrm{S}\right)$ do gênero, Sub-região Patagônica da Região Andina, em elevações entre 1500 e 3000 m, onde as temperaturas mínimas anuais chegam a $4^{\circ} \mathrm{C}$. Cabe destacar que não há coletas recentes de $A$. adenotricha, que está listada no Livro Vermelho para a Conservação da IV Região de Coquimbo (Cavieres et al. 2001 ), com uma anotação (EX?), significando que não se conhecem coletas recentes e que pode estar extinta. 

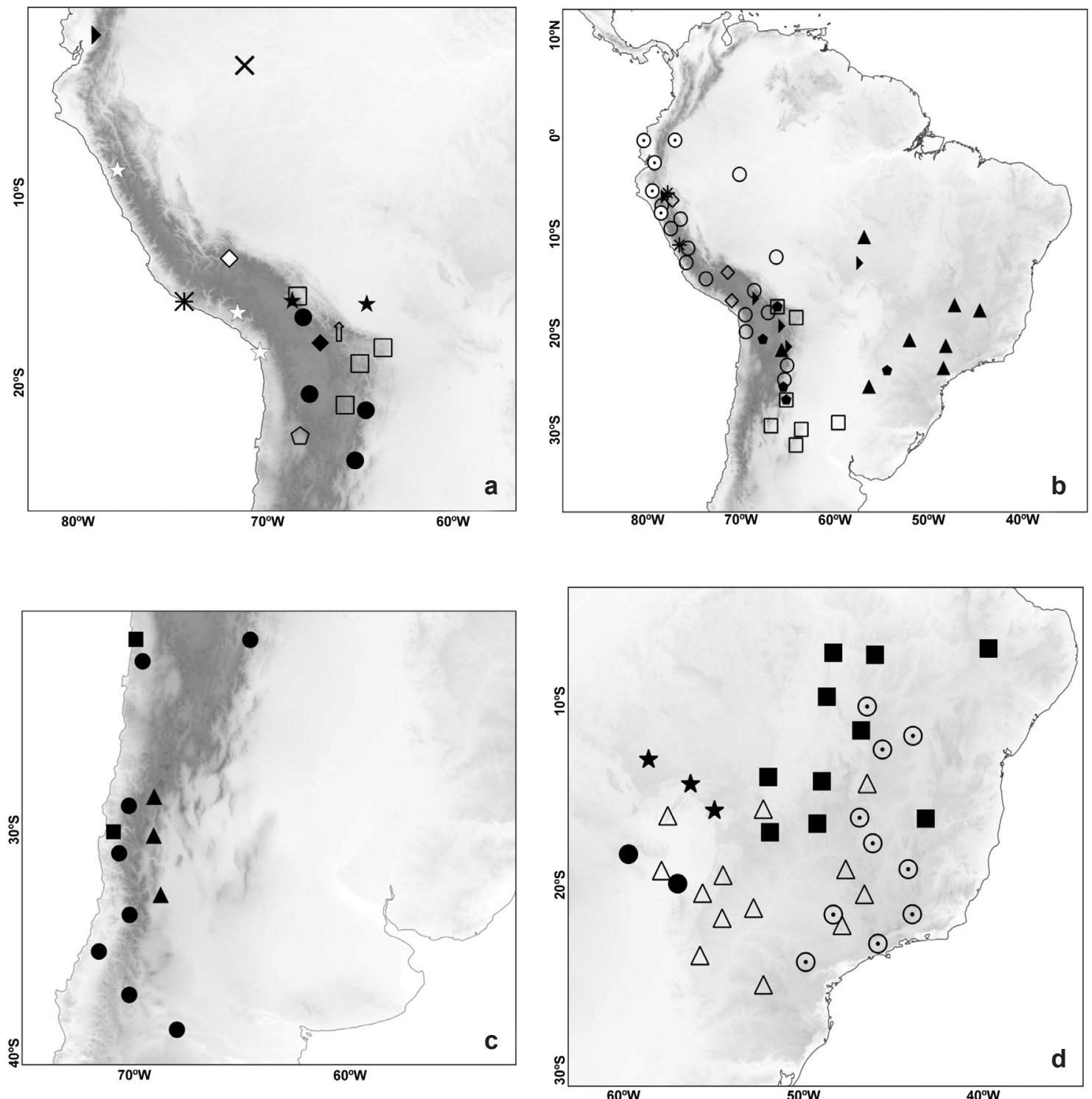

Figura 2 - Distribuição de Aldama na América do Sul - a. espécies exclusivas da Zona de Transição Sul-americana

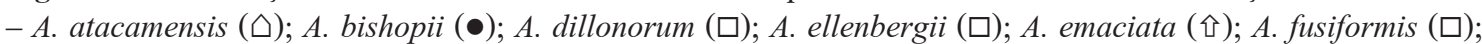
A. lanceolata $(\square)$; A. media $(\mathrm{X}) ;$ A. peruviana $(\boldsymbol{\xi}) ;$ A retroreflexa $(\mathbf{\square})$; A. soridoi $(\square)$; b. espécies Neotropicaistransicionais não ocorrentes ou não exclusivas do Cerrado - A. australis ( ); A. brittonii ( $\square)$; A. helianthoides $(\square)$; A. incana $(\odot)$; A. macrorhiza $(\mathbf{\Delta}) ;$ A. mollis $(\bullet)$; A. tucumanensis $(\square) ;$ A. truxilensis $(\square)$; c. espécies Andinotransicionais $-A$. adenotricha $(\mathbf{\square})$; A. gilliesii $(\mathbf{\Delta})$; A. revoluta $(\bullet)$; d. espécies Neotropicais não transicionais exclusivas da Província do Cerrado - A. corumbensis $(\bullet)$; A. squalida $(\triangle)$, não endêmicas do Brasil e com área core no estado de Mato Grosso do Sul; A. oblongifolia (ם); A. vernonioides ( $\star$ ), exclusiva do território brasileiro, com área core no estado de Mato Grosso do Sul; $A$. robusta $(\bullet)$, espécie brasileira de ampla distribuição.

Figure 2 - Distribution of Aldama in South America - a. exclusive species of the South American Transition Zone - A. atacamensis ( $\triangle)$;

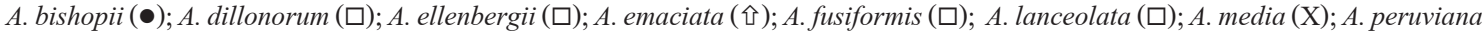
(ঊ); A retroreflexa $(\square)$; A. soridoi $(\square)$; b. Neotropical-transitional species not occurring or not exclusive to Cerrado - A. australis $(\triangleright) ;$ A. brittonii $(\square) ;$ A. helianthoides $(\square)$; A. incana $(\odot) ;$ A. macrorhiza $(\mathbf{\Delta}) ;$ A. mollis $(\bullet)$; A. tucumanensis $(\square)$; A. truxilensis $(\square)$; c. Andean-transitional species - A. adenotricha $(\mathbf{\square})$; A. gilliesii $(\mathbf{\Delta})$; A. revoluta $(\bullet)$; d. Neotropical no transitional species exclusive of Cerrado Province $-A$. corumbensis $(\bullet)$; A. squalida $(\triangle)$, not endemic to Brazil and with core area in the state of Mato Grosso do Sul; A. oblongifolia $(\square)$; A. vernonioides $(\star)$, exclusive of the Brazilian territory, with core area in the state of Mato Grosso do Sul; $A$. robusta $(\bullet)$, a widely distributed Brazilian species. 
Na porção mais alta das Yungas peruanas, em altitudes entre 2300 a $2235 \mathrm{~m}$ e temperaturas médias anuais por volta de $16^{\circ}$ são encontradas A. Australis, A. brittonii e A. truxilensis (mesotérmicas) (Fig. 2b). A última espécie consta no livro de espécies endêmicas do Perú (Beltrán et al. 2006) como uma planta vulnerável à extinção, por ser dependente de chuvas sazonais e pela expansão das atividades agrícolas.

$\mathrm{Na}$ porção setentrional do Peru, entre os páramos ao Norte e a Puna ao Sul, em altitudes acima de $3000 \mathrm{~m}$, existem comunidades alpinas transicionais conhecidas localmente como formações Jalca (Weberbauer 1936) e limitadas bruscamente por $4,5-8^{\circ} \mathrm{S}$ e $77-80^{\circ} \mathrm{W}$ (Dillon 1994-2010). São locais mais secos que os páramos e mais úmidos que a Puna; Luteyn (1999) sugeriu que essa formação é similar aos páramos andinos do Sul do Equador, mas a região parece representar uma barreira para a migração entre espécies do Equador e Peru, superada apenas por $A$. helianthoides, espécie com alta capacidade de adaptação e encontrada também em várias províncias da Região Neotropical e da Zona de Transição Sul-americana.

Entre 4-6 ${ }^{\circ} \mathrm{S}$ existe uma descontinuidade nos Andes atravessando, no sentido noroeste-nordeste, os Departamentos de Piura e Cajamarca com as montanhas se tornando fragmentadas, resultando em uma passagem de baixa altitude (menos de 3000 metros) para a biota; é a Depressão de Huancabamba, uma região geograficamente complexa, com vales entre as montanhas, onde corre um intrincado sistema fluvial que alcança o Equador. Apenas A. helianthoides e A. incana (Fig. 2b) superam essa barreira.

Os desertos Peruviano e Atacama formam um cinturão que ocupa cerca de um terço da costa oeste da América do Sul e estão entre os mais secos da terra; a flora local é megatérmica e dependente da neblina (formação Lomas, 0-1000 m.s.m.) e está estimada em mais de 1100 espécies de fanerógamas (Dillon 1994-2010). A aridez dos diversos pontos é controlada por fatores como a existência de breves períodos de chuva associados a eventos raros, mas recorrentes, de "El Niño" (Dillon \& Rundel 1990) e pela estabilidade nos padrões de temperatura ao longo do ano, devido à relação entre a superfície fria do mar e correntes de Humboldt (Peruvianas), com a formação de estratos de nuvens abaixo de 1000 m.s.m., durante os meses de inverno (Prohaska 1973). A formação Lomas é constituída de comunidades discretas ou ilhas de vegetação separadas por habitats extremamente áridos, destituídos de vida vegetal. O grau de endemismo é alto $(40 \%)$; vários gêneros primariamente do Hemisfério Norte têm espécies endêmicas nos desertos costeiros e esse é o caso de Aldama, com A. dillonorum e A. peruviana no Peru (Fig. 2a).

Apesar da continuidade do deserto do Peru ao Chile, a ausência de uma condição topográfica provendo neblina entre Arica e Anfogasta (norte do Chile) resulta no fato de menos de $7 \%$ das espécies serem encontradas dos dois lados dessa formação (Dillon \& Rundel 1990): do lado chileno, onde aparentemente, a região de maior concentração em número de indivíduos é a Província de Coquimbo, ocorrem $A$. adenotricha, $A$. gilliesii e $A$. revoluta (Fig. 2c). Nesta região, $A$. adenotricha e $A$. revoluta são encontradas nas Lomas, a cerca de $800 \mathrm{~m}$ de altitude ou seguem cruzando os Andes, do Chile à Argentina, em altitudes que chegam a $3500 \mathrm{~m}$, alcançando a Sub-região Chilena Central da Região Andina. De acordo com as evidências, essas duas espécies podem ser classificadas como mega, meso ou microtérmicas. A outra espécie a alcançar o cone sul da América do Sul, A. gilliesii, está mais bem representada na Argentina, na Província de Puna da Zona de Trasnsição Sul-americana, mas chega à Província de Coquimbo, da Sub-região Chilena Central; é uma espécie primariamente mesotérmica e ocasionalmente microtérmica.

A Zona de Transição Sul-americana estendese ao longo das montanhas da Cordilheira dos Andes entre Venezuela ocidental e norte do Chile e centro-oeste da Argentina. As Províncias de Prepuna, Deserto e Monte, foram enquadradas nessa zona por Morrone (2006, 2014b, 2015) devido às estreitas ligações bióticas com a Puna andina e com o Páramo do Norte andino. A entomofauna da Zona de Transição Sul-americana mostra uma sobreposição de táxons andinos e neotropicais de insetos (Morrone 2006) e o mesmo acontece com várias espécies de Aldama, mas 10 espécies são exclusivas dessa Zona (Fig. 2).

No Brasil, as condições mais favoráveis à diversidade e densidade populacional de Aldama estão em áreas com climas megatérmicos (a grande maioria das espécies exclusivamente brasileiras) ou mesotérmicos (14 espécies, sendo sete exclusivas do Brasil) que se enquadram nos seguintes tipos classificados por Köppen (Alvares et al. 2013): Aw, Cwa (que condicionam a paisagem dos cerrados, acima de $500 \mathrm{~m}$ ), Cfa, na região dos Pampas, e raramente $\mathrm{Cwb}$, em áreas abertas ou manchas de cerrado das Províncias das Florestas de Araucária, do Paraná e Atlântica. A maior diversidade de Aldama 
nesses ambientes pode estar ligada ao seu sistema subterrâneo espessado (Magenta 2006; Magenta et al. 2010; Magenta \& Pirani 2014) característico de muitas plantas adaptadas aos solos de cerrado, pobres em nutrientes (Gottsberger \& SilberbauerGottsberger 2006, Simon \& Pennington 2012) e que proveria necessidades hídricas na estação seca e proteção contra fogo, pois reservam água (e.g., Fahn 1964; Coutinho 1982) e apresentam revestimento espessado e resistente. Além disso, esses sistemas subterrâneos acumulam grandes quantidades de frutano (Silva et al. 2014), que funcionam como reservas e parecem também estar relacionados à tolerância à seca (Vijn \& Smeekens 1999) e às baixas temperaturas (Alberdi et al. 2002).

Nos Pampas, onde se distribuem principalmente os grupos de gramíneas mesotérmicos (os microtérmicos representam transgressões) do Domínio Chaquenho, da Sub-região Chaquenha (Região Neotropical), é encontrada, em profusão $A$. anchusifolia, que chega às províncias biogeográficas das Florestas Atlântica, do Paraná e de Araucária, o que também ocorre com A. pilosa, com número bem menor de populações. Exclusivas da Província Pampeana (Fig. 3d) são A. breviflosculosa (Uruguai), A. knobiana, A. megapotamica, A. meridionalis e A. nudicaulis (Brasil), todas mesotérmicas.

As espécies brasileiras que alcançam altitudes acima de $1500 \mathrm{~m}$ são $A$. bracteata, $A$. filifolia, $A$. gardneri (Fig. 3b), A. grandiflora e A. robusta (Fig. 2d), em locais com temperatura média anual em torno dos $20^{\circ} \mathrm{C}$ (Alto Paraíso de Goiás, Rio de Contas e Airuoca) sendo, portanto megatérmicas.

\section{Padrões de distribuição}

Com os dados tabulados da forma exposta acima e expressos na Tabela 1, propomos os seguintes padrões espaciais observados nas espécies de Aldama na América do Sul, enquadrados na divisão de Morrone (2014b, 2015):

\section{Espécies exclusivas da Zona de Transição Sul- americana: 10 espécies (Fig. 2a).}

Aldama bishoppi, A. ellenbergii, A. emaciata, A. fusiformis, A. lanceolata e A. retroreflexa são restritas à Província de Puna. Aparentemente, $A$. fusiformis é endêmica da Bolívia. Com exceção de $A$. ellenbergii, restrita ao Domínio Campestre Temperado, as demais alcançam o Domínio Tropical e Subtropical (Burkart 1975). Entre as espécies que ocorrem no Domínio Campestre de países Frios, $A$. atacamensis, é endêmica da
Região do Atacama, no Chile e $A$. dillonorum e $A$. peruviana são encontradas apenas na Província do Deserto, no Peru.

2. Espécies Neotropicais-transicionais: espécies que ocorrem primariamente na Zona de Transição Sul-americana, com intrusões em outras partes da Região Neotropical: oito espécies (Fig. 2b).

Aldama brittonii e A. truxillensis ocorrem nas Províncias do Deserto, de Punas e de Yungas, da Sub-região Brasileira. A. incana é encontrada desde a Província do Páramo, no Equador, até o Peru (Província do Deserto). A. tucumanensis tem a maior concentração populacional na Província Puna, mas alcança as Províncias do Chaco e Pampeana. A. mollis concentra-se principalmente nas Províncias de Puna e do Monte, mas é encontrada pontualmente nas Províncias Chaquenha e Pampeana. A. helianthoides parece ter sua área-core na Província de Puna, mais específicamente nas Punas bolivianas, e se estender ao longo da Província da Prepuna para o Norte, até chegar à Província do Páramo, no Equador, e para o Sul, até o Noroeste da Argentina. A. australis ocorre de forma contínua ou quase contínua, desde a Província de Yungas, no Domínio Sul-Brasileiro (Morrone 2014b), até a Província Chaquenha. Finalmente, $V$. macrorhiza é encontrada nas Províncias de Puna (Argentina e Bolívia) e da Floresta do Paraná (Paraguai e sudoeste do estado do Paraná, no Brasil) e estende-se à Província do Cerrado, chegando às regiões central e sudeste do estado de São Paulo e alcançando as regiões nordeste e central do estado de Minas Gerais, além de possuir dois registros de mais de 50 anos atrás no Mato Grosso do Sul. Atualmente, no Brasil V. macrorhiza parece estar restrita a áreas de preservação, onde floresce na primavera ou raramente no inverno e frutifica no verão.

Três espécies se enquadram, pela classificação de Burkart (1975) no Domínio de Países Frios ( $A$. incana, A. brittonii e $A$. truxilensis); uma transita entre o Domínio Campestre Tropical e Subtropical e o Domínio Campestre temperado (A. tucumanensis) e duas (A. australis e A. helianthoides) ocorrem nos três Domínios.

3. Espécies Andino-transicionais: Espécies que ocorrem da Zona de Transição Sul-americana à Região Andina: três espécies (Fig. 2c).

Aldama revoluta (Fig. 4a) parece ter sua áreacore na Província de Coquimbo (Região Andina), alcançando ao Sul, a Província da Patagônia e, ao 

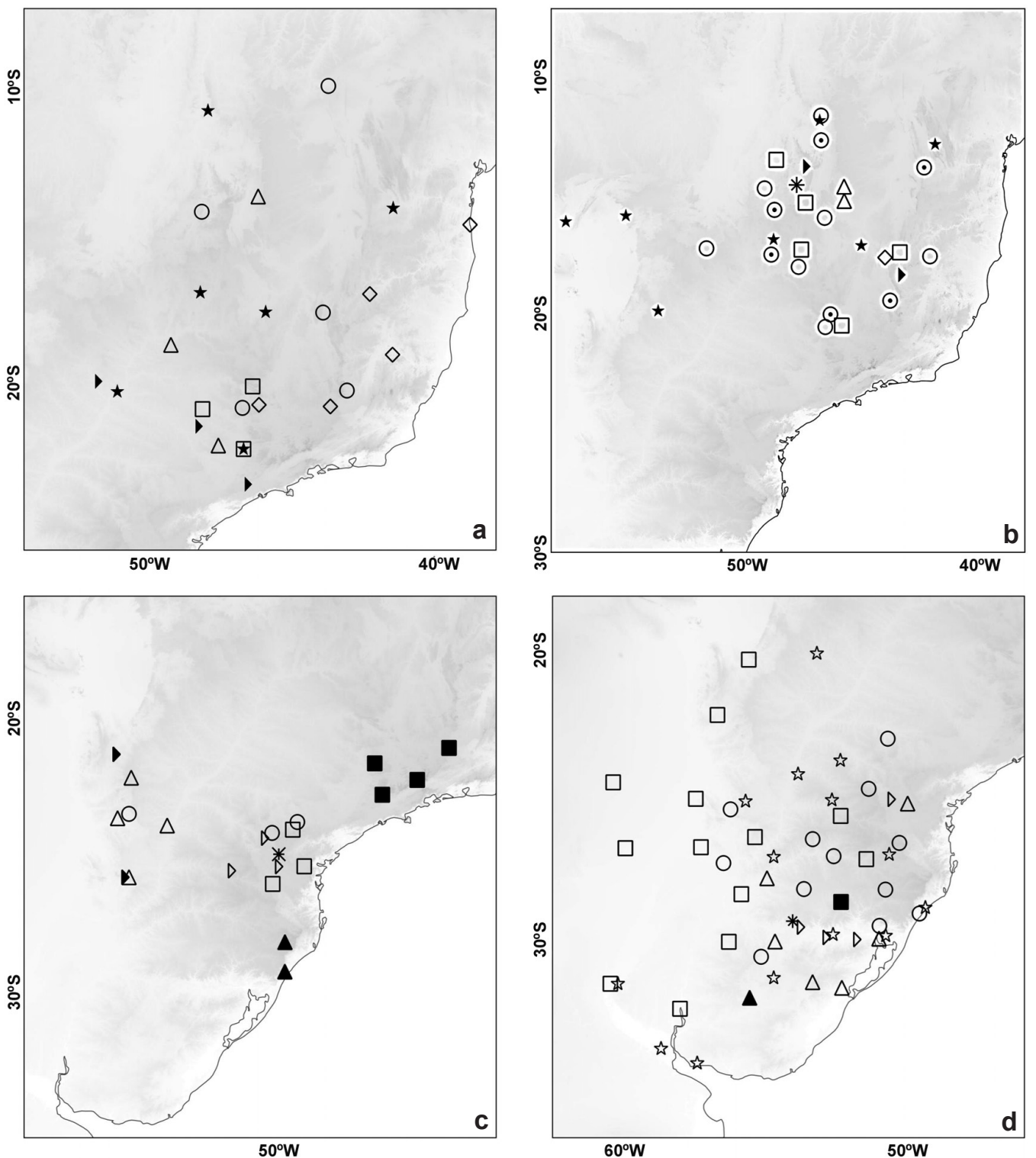

Figura 3 - Distribuição de Aldama na América do Sul. Espécies Neotropicais não transicionais - a-b. espécies endêmicas do Brasil, exclusivas da Província do Cerrado - a. táxons com limite Sul no estado de São Paulo - A. arenaria ( $\square)$; A. bakeriana $(\square)$; A.discolor $(\square)$; A. goiazii $(\triangle)$; A. rubra $(\triangleright)$; A. tenuifolia $(\square)$; b. táxons com limite Sul no estado de Minas Gerais $-A$. bracteata $(\odot)$; A. filifolia $(\triangleright)$; A. gardneri $(\square)$; A goyazensis $(\square)$; A. grandiflora $(\square)$; A. kunthiana $(\square)$; A. laxicmosa $(\square)$ A. veredensis $(\triangle)$; c. táxons encontrados nas províncias das Florestas de Araucária e/ou do Paraná com incursões à Província do Cerrado - A. amphychlora $(\square)$; A. aspilioides $(\square)$; A. linearifolia $(\triangle)$; A. nudibasilaris $(\square)$; A. paranensis $(\square)$; A. pilicaulis $(\triangleright) ;$ A. santacatarinensis $(\boldsymbol{\Lambda}) ;$ A. trichophylla $(\square)$; d. táxons que ocorrem primariamente na Província Pampeana, com algumas

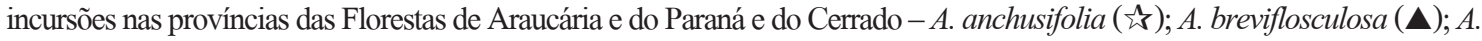
knobiana $(\square) ;$ A. megapotamica $(\square)$; A. meridionalis $(\square) ;$ A. nudicaulis $(\triangle)$; A. pilosa $(\square) ;$ A. tuberosa $(\square)$.

Figure 3 - Aldama distribution in South America. Neotropical nontransitional species - a-b. endemic species from Brazil, exclusive to the Cerrado Province; a. taxa with southern limits in the state of São Paulo - A. arenaria ( $\square)$; A. bakeriana $(\square)$; A.discolor $(\square)$; A. goiazii $(\triangle) ;$ A. rubra $(\triangleright)$; A. tenuifolia $(\square)$; b. taxa with southern limit in the state of Minas Gerais - A. bracteata $(\odot) ;$ A. filifolia $(\triangleright) ;$ A. gardneri $(\square) ;$ A. goyazensis $(\square) ; A$. grandiflora $(\square)$; A. kunthiana $(\square)$; A. laxicmosa $(\square)$ A. veredensis $(\triangle)$; c. taxa found in the provinces of Araucaria and /or Parana Forest with forays into the Cerrado Province - A. amphychlora $(\square)$; A. aspilioides $(\square)$; A. linearifolia $(\triangle)$; A. nudibasilaris $(\square)$; A. paranensis $(\square)$; A. pilicaulis $(\square)$; A. santacatarinensis A. ( $\mathbf{\Delta})$; A. trichophylla $(\square)$; d. taxa with primary occurrence in the Pampean Province, with some incursions in the provinces of

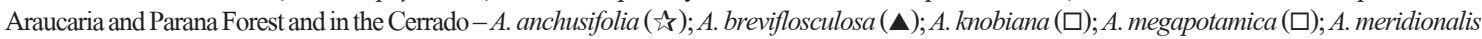
(匹); A. nudicaulis ( $\triangle)$; A. pilosa $(\square) ;$ A. tuberosa $(\square)$. 
Norte (seguindo pelas Províncias de Prepunas e Punas) a Província do Deserto, na Zona de Transição Sul-americana. Outra espécie que cruza os Andes, desde a Província da Prepuna, no Chile, até a Província de Maule, na Sub-região Subantártica da Região Andina da Argentina é $A$. gilliesii. A maior concentração de espécimes provém das Punas da Argentina.

Aldama gilliesii ocorre em nos Domínios Campestre Tropical e Subtropical e Campestre de Países Frios e $A$. revoluta transita pelos três Domínios de gramíneas.

4. Espécies Neotropicais não transicionais: Espécies exclusivas da Região Neotropical, que não ocorrem na Zona de Transição Sul-americana: 41 espécies (Fig. 3).

Na Província da Puna, no Equador, ocorrem as espécies endêmicas $A$. media e $A$. soridoi. Esses táxons estão em listas de espécies ameaçadas: $A$. media, categorizada como Criticamente em Perigo (CR) ou possivelmente extinta pelos critérios da IUCN, por não haver exemplares dessa espécie nos herbários do Equador e A. sodiroi, registrada apenas por quatro coletas feitas nos Andes centrais e categorizada como vulnerável (VU), devido à drástica redução de seu habitat (Montúfar \& Pitman 2003a, 2003b).

Exclusivas da Província Pampeana da Sub-região Chaquenha, encontram-se espécies mesotérmicas, exclusivas dos Pampas do Uruguai (A. breviflosculosa), e do Brasil (A. knobiana, A. meridionalis e $A$. nudicaulis). É preciso salientar que A. breviflosculosa, A. knobiana e A. meridionalis são conhecidas apenas pelo material-tipo. Outra espécie mesotérmica, A. megapotamica, foi coletada na Província Pampeana, na porção central do Rio grande do Sul, e em um único ponto de Santa Catarina, no município de Curitibanos, na Província da Floresta de Araucaria.

Compreendendo uma grande região que abrange as Províncias Chaquenha, Pampeana, Floresta do Paraná, Floresta Atlântica e Floresta de Araucária, está a distribuição de duas espécies, também mesotérmicas, $A$. anchusifolia e A. pilosa, com limite Sul nos Pampas Uruguaios. A. tuberosa é encontrada em climas mesotérmicos e megatérmicos no Brasil, em ocorrências esparsas no Rio Grande do Sul, Paraná e Mato Grosso do Sul, onde se espalha pelas Províncias Pampeana, Floresta de Araucária e Cerrado; habita também a Província Pampeana da Argentina, do Paraguai e do Uruguai, alcançando, nos dois primeiros, a Província Chaquenha. Duas espécies megatérmicas endêmicas do Brasil, $A$. aspilioides $\mathrm{e}$ A. trichophylla, ocorrem na Província de Araucárias (a segunda também possui alguns poucos representantes na Província do Paraná, no extremo Sul do estado com mesmo nome). Nas encostas cobertas por Mata Atlântica (Província da Floresta Atlântica) das Serras Catarinense e Gaúcha, e na região dos Aparados da Serra do Rio Grande do Sul (Províncias Floresta do Paraná e Floresta de Araucária), encontra-se $A$. santacatarinensis, uma espécie mega ou mesotérmica bastante peculiar, pois vegetativamente seus representantes se assemelham aos de Verbesina, e possuem brácteas involucrais cirrosas, características do gênero Helianthus. Aldama nudibasilaris distribui-se entre as Províncias da Floresta do Paraná (sempre nas bordas, como mesotérmica) e do Cerrado (megatérmica).

Quatro espécies megatérmicas encontradas no Brasil foram inicialmente descritas apenas para o Paraguai: A. amphychlora, A. linearifolia, A. macrorhiza e A. pilicaulis (Província da Floresta do Paraná), ocorrendo nas regiões de Savana das Serras de Maracayú, Caaguazuú e Amambay. No Brasil, A. amphychlora está restrita a uma região do estado do Paraná, na Província fitogeográfica de Floresta do Paraná, que abrange os municípios de Arapoti, Sengés e Telêmaco Borba, encravados em uma área de transição entre fisionomias de Floresta Estacional Semidecidual e Floresta Ombrófila Mista, com remanescentes de Cerrado e pertencentes à Area de Proteção Ambiental da Escarpa Devoniana. $A$. linearifolia foi coletada apenas em Ponta Porã, no Mato Grosso do Sul (Província do Cerrado), na divisa com o Paraguai, onde ocorre na Província do Paraná.

É importante ressaltar que as espécies de Aldama cuja ocorrência abrange Províncias de Floresta, existem nelas apenas em clareiras, beiras de estrada ou encraves de campo ou cerrado, sendo um indicativo que reforça a marcada expressividade do gênero em ambientes com maior luminosidade e menor umidade. É caso de $A$. trichophylla (Fig. 4b) que, como já foi mencionado, é encontrada em bordas de mata, nas Províncias de Floresta de Araucária e do Paraná.

A maioria das espécies exclusivamente brasileiras é encontrada unicamente na Província do Cerrado, com A. robusta (Fig. 4c), apresentando uma distribuição contínua em toda a Província. Duas espécies descritas inicialmente como exclusivamente brasileiras foram encontradas recentemente na Bolívia: A. corumbensis e A. squalida (Montanha 
Roboré e Cerro Mutún). No Brasil, a primeira é conhecida apenas nos Municípios de Corumbá e Miranda, no estado do Mato Grosso do Sul e a segunda ocorre nos estados de Mato Grosso, Mato Grosso do Sul, Goiás e Minas Gerais, apresentando grandes variações fenotípicas, atingindo mais de 2 $\mathrm{m}$ de altura e apresentando folhas oval-lanceoladas e membranáceas na região do Pantanal, ou com menos de $0,5 \mathrm{~m}$ e folhas orbiculares cartáceas, no alto de morrarias com sedimentos ferríferos.
Seis espécies têm como limite Sul o estado de São Paulo: A. arenaria estendendo-se no sentido Nordeste; $A$. rubra estendendo-se raramente para Oeste; A. bakeriana, A. discolor (Fig. 4e), A. goyazii e $A$. tenuifolia aparentemente com área-core no estado de Minas Gerais e alcançando os limites Sul (São Paulo) e Noroeste (Goiás e Tocantins). Destas, A. goyasii e A. rubra, são exclusivamente megatérmicas e as demais podem ocorrer como mega ou mesotérmicas, distribuindo-se em áreas
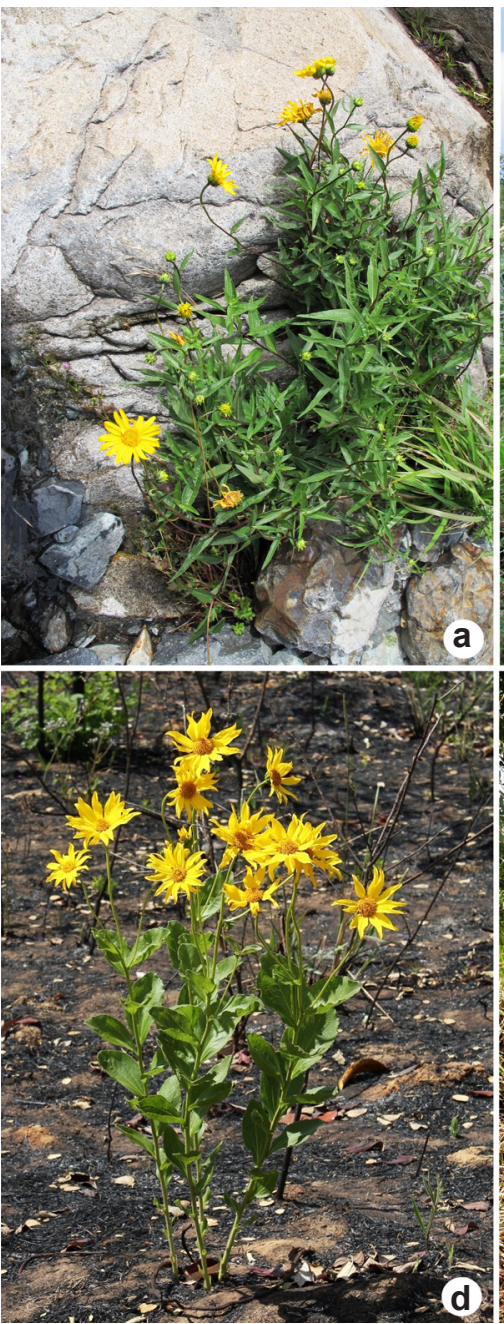
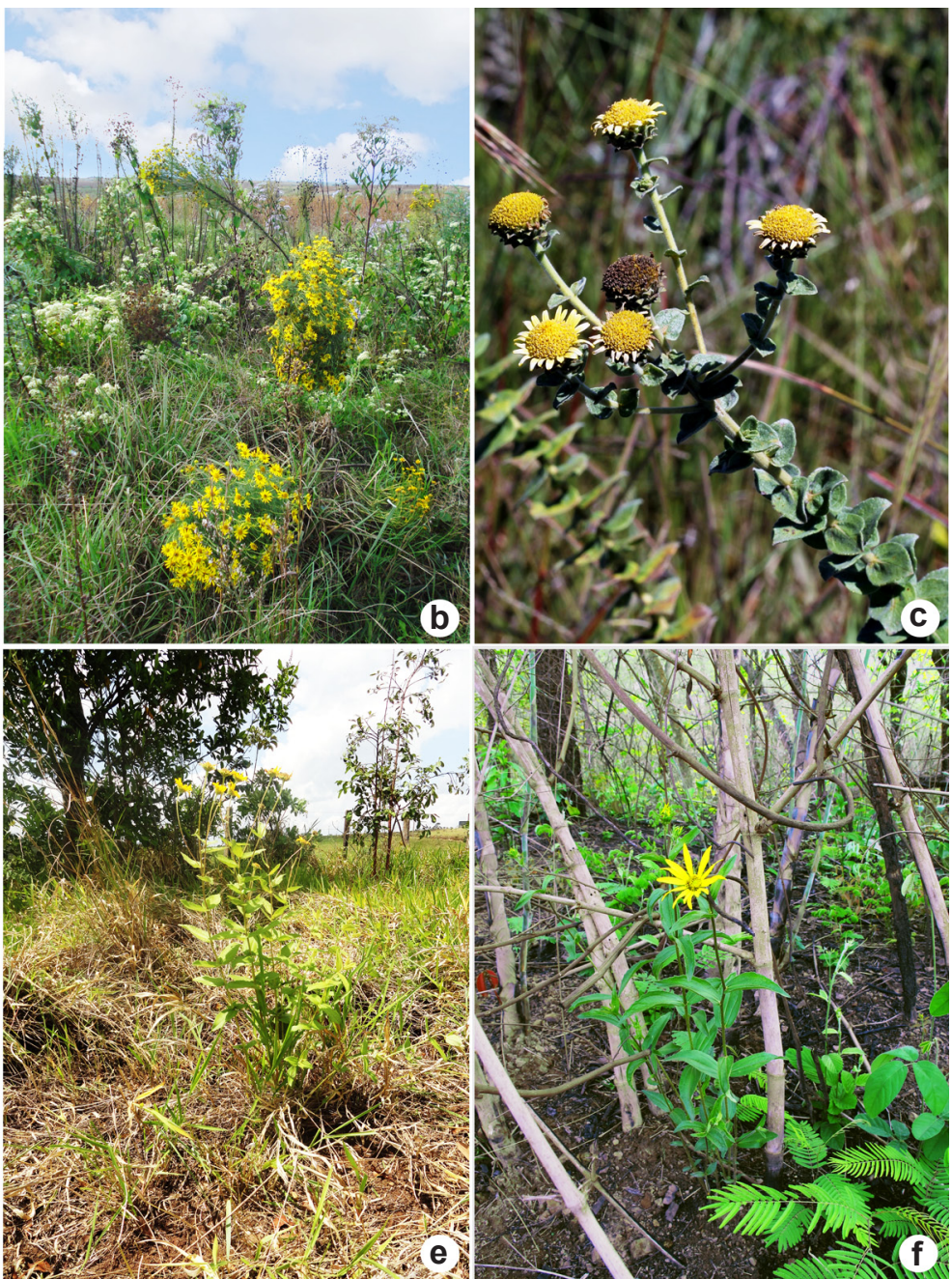

Figura 4 -Espécies de Aldama -a. A. revoluta: espécie Andino-Transicional. b-f. espécies Neotropicais não transicionais -b. A. trichophylla: encontrada nas Províncias da Floresta de Araucária e do Paraná; c. A. robusta: com ampla distribuição; d-f. espécies exclusivas da Província do Cerrado - d. A. grandiflora: com limite Sul no estado de Minas Gerais (Brasil); e. A. discolor: com limite Sul no estado de São Paulo (Brasil); f. A. squalida: com área core no estado do Mato Grosso do Sul (Brasil). (a,f. Benoit Loeuille; c,d. Marurício Mercadante; b,e. Aline Bombo).

Figure 4 - Aldama species - a. A. revoluta: Andean transitional species. b-f. Neotropical nontransitional species - b. A. trichophylla: found in Provinces of Araucaria and Parana Forest; c. A. robusta: with wide distribution; d-f. exclusive species of the Cerrado Province $-\mathrm{d}$. $A$. grandiflora: southern limit in the state of Minas Gerais (Brazil); e. A. discolor: southern limit in the state of São Paulo (Brazil); f. A squalida: with core area in the state of Mato grosso do Sul (Brazil) (a,f. Benoit Loeuille; c,d. Marurício Mercadante; b,e. Aline Bombo). 
com clima temperado úmido de inverno seco, com verão quente ou temperado ( $\mathrm{Cwa}$ e $\mathrm{Cwb}$ de Köppen).

Oito táxons têm limite Sul a partir de Minas Gerais (A. bracteata, A. filifolia, A. gardneri, A. goyasensis, A. grandiflora (Fig. 4d), A. kunthiana, A. laxicymosa e $A$. veredensis), em regiões de clima tropical com inverno seco (Aw de Köpen) e sua área-core é a região dos estados de Goiás e do
Nordeste de Minas Gerais, com extensões para o Norte, até o Sul da Bahia e o Tocantins, e para o Oeste, no Mato Grosso.

Uma espécie aparentemente tem área-core no estado de Goiás (A. oblongifolia), e outra ocorre exclusivamente no estado de Mato Grosso ( $A$. vernonioides). De acordo com os dados disponíveis na literatura, o limite de distribuição das espécies ao Norte é em torno de $11^{\circ} \mathrm{S}$, mas A. oblongifolia

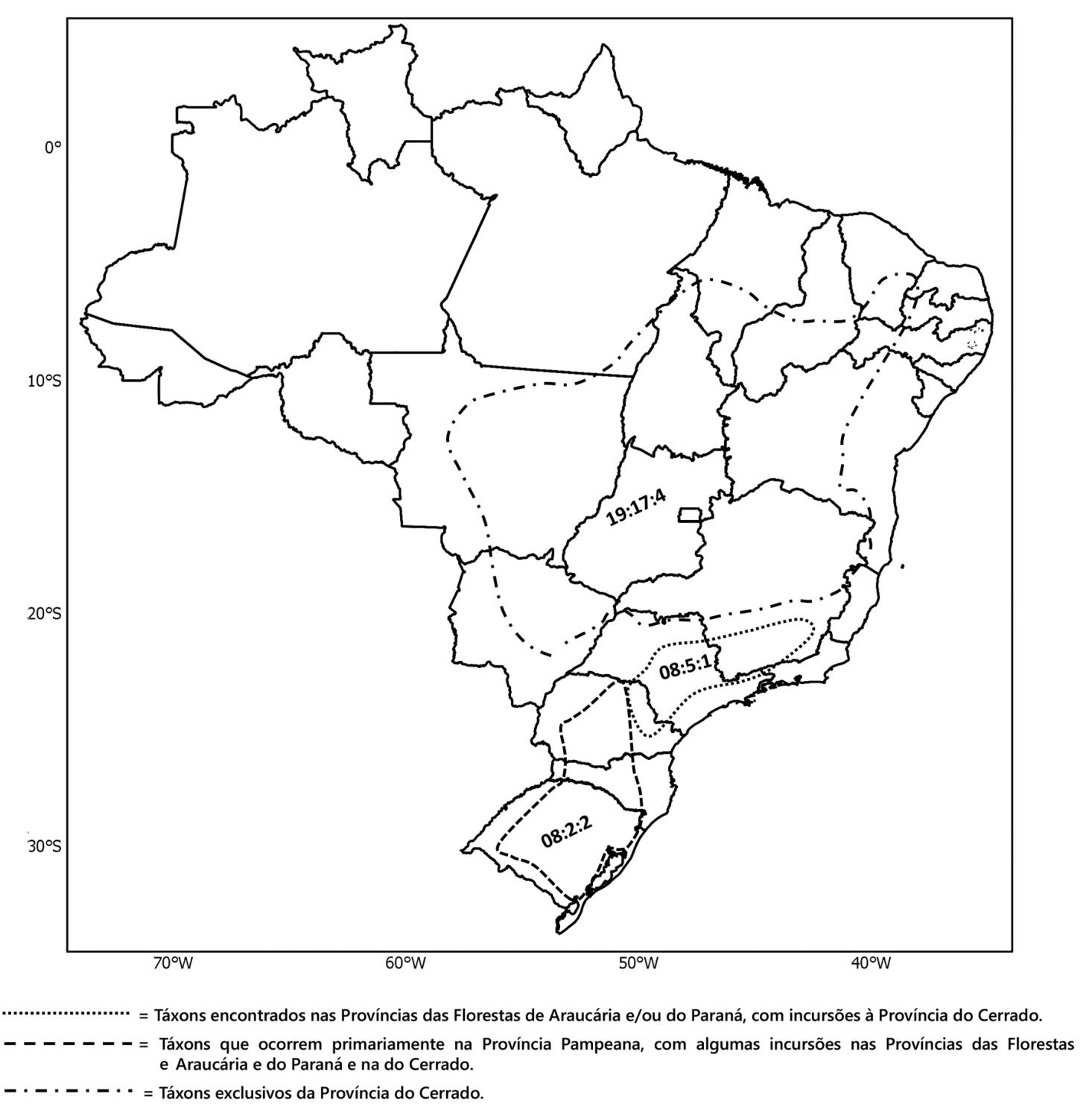

Figura 5 - Padrões de distribuição das espécies de Aldama no Brasil. As linhas pontilhadas delimitam áreas de distribuição dos conjuntos de espécies que constituem os padrões. As séries numéricas em cada área indicam: total de espécies na área: espécies endêmicas do Brasil: espécies descritas nas últimas duas décadas.

Figure 5-Distribution patterns of Aldama species in Brazil. The dotted lines delimit the areas of distribution belonging to each group of species that constitute said patterns. The numerical series in each area indicate: total species in the area: endemic species from Brazil: species described in the last two decades. 
apresenta poucas ocorrências em latitudes entre 7 e $8^{\circ} \mathrm{S}$. Não há registros em longitudes inferiores a $40^{\circ} \mathrm{W}$.

Um grande número de espécies deste padrão (29 spp.) pode ser incluído no Domínio Campestre Tropical e Subtropical de Burkart (1975); oito delas ocorrem no Domínio Campestre Temperado, e duas transitam entre o Domínio Campestre Tropical e Subtropical e o Domínio Campestre de Países Frios.

No Brasil, a maioria das espécies (19 spp.) ocorre exclusivamente em área de Cerrado; oito são encontradas primariamente na Província Pampeana, com algumas alcançando áreas de cerrado, e outras oito existem nas Províncias das Florestas de Araucária e/ou do Paraná (Fig. 5).

Aldama constitui mais um exemplo de gênero neotropical com centro de diversidade nas partes tropicais da América do Sul, com algumas espécies estendendo sua distribuição além desses limites, ou poucas restritas fora deles, em ambos os casos, inclusive em climas montanos e frios. Deve-se destacar que o fato de Aldama ter, no Brasil, sua maior riqueza de espécies em cerrado (Fig. 5), mas com algumas ocorrências em orla de mata, nas Províncias Florestais, e outras em climas frios indica que, possivelmente, se trata de um grupo como aqueles sugeridos por Lomolino et al. (2006), que exibem algum conservantismo de nicho tropical, determinado por traços intrínsecos dessas plantas, como ecofisiologia, e que podem se manter por longas escalas evolucionárias.

Os padrões espaciais aqui propostos para Aldama, assim como os de Schefflera do Brasil extra-amazônico (Fiaschi \& Pirani 2008) e de um grupo de Chamaecrista (Rando \& Pirani 2011), não são suficientes para a proposta de uma hipótese sobre a evolução do grupo. A falta de registros fósseis não permite a incorporação de um enquadramento no tempo, para um melhor entendimento da biogeografia histórica do grupo, como afirmaram Loeuille et al. (2015) no estudo filogenético de Lychnophorinae (Vernonieae, Asteraceae). Esperase que análises filogenéticas futuras forneçam hipóteses robustas de relacionamento entre as espécies de Aldama e, ao incluírem datação molecular, venham a elucidar aspectos importantes sobre os fatores envolvidos na determinação dos padrões de distribuição aqui apresentados e da história biogeográfica e de diversificação do grupo.

\section{Agradecimentos}

Agradecemos aos curadores dos herbários visitados ou contatados, a disponibilização das coleções e envio de imagens de tipos, e em especial, ao Dr. David J. Nicholas Hind do Royal Botanic Garden - Kew, as discussões nomenclaturais sobre Viguiera s.1. Aos pesquisadores Andrés MoreiraMuñoz, Claudio Augusto Mondin e Fernando Batista da Costa, o auxílio em trabalhos de campo. À Fundação de Amparo à Pesquisa do Estado de São Paulo (FAPESP - Projeto Temático no 2010/51454-3), o suporte financeiro concedido. O segundo autor agradece ao $\mathrm{CNPq}$, o apoio por meio de bolsa de Produtividade em Pesquisa.

\section{Referências}

Alberdi, M.; Bravo, L.A.; Gutiérrez, A.; Gidekel, M. \& Corcuera, L.J. 2002. Ecophysiology of Antarctic vascular plants. Physiologia Plantarum 115: 479486. Disponível em < http://onlinelibrary.wiley.com/ doi/10.1034/j.1399-3054.2002.1150401.x/full>. Acesso em 2 maio 2015.

Alvares, C.A.; Stape, J.L.; Sentelhas, P.C.; Gonçalves, J.L.M. \& Sparovek, G. 2013. Köppen's climate classification map for Brazil. Meteorolgiske Zeitschrift 22: 711-728. Disponível em <www. schweizerbart.de/papers/metz/detail/22/82078/ Koppens_climate_classification_map_for_Brazil $>$. Acesso em 2 maio 2015.

Beltrán, H.; Granda, A.; León, B.; Sagástegui, A.; Sánchez, I. \& Zapata, M. 2006. Asteraceae endémicas del Perú. Revista Peruana de Biologia 13: 64s-164s. Disponível em <http://sisbib.unmsm.edu. pe/bvrevistas/biologia/v13n2/pdf/a16.pdf $>$. Acesso em 20 maio 2015.

Blake, S.F. 1918. A revision of the genus Viguiera. Contributions from the Gray Herbarium of Harvard University 54: 1-205. Disponível em <www.jstor. org/stable/41763960>. Acesso em 15 maio 2015.

Burkart, A. 1975. Evolution of grasses and grasslands in South America. Taxon 24: 53-66.

Cavieres, L.A.; Mihoc, M.; Marticorena, A.; Marticorena, C.; Matthei, O. \&. Squeo, F.A. 2001. Determinación de áreas prioritarias para la conservación: análisis de parsimonia de endemismos (PAE) en la flora de la IV Región de Coquimbo. In: Squeo, F.A.; Arancio, G. \& Gutiérrez, J. Libro rojo de la flora nativa de la región de Coquimbo y de los sitios prioritarios para su conservación. Ediciones de la Universidad de La Serena, La Serena. Pp. 159-170. Disponível em $<$ www.biouls.cl/lrojo/Manuscrito/Capitulo $\% 20$ 10\%20PAE.PDF $>$. Acesso em 2 maio 2015.

Coutinho, L.M. 1982. Ecological effects of fire in Brazilian cerrado. In: Huntley, B.J. \& Walker, B.H. Ecology of tropical savannas. Springer, Berlin. Pp. 273-291.

Delgadillo, C. 1992. Moss interchange: bryofloristic similarities between Mexico and Colombia and the phytogeographical role of the Central American bridge. Bryologist 95: 261-265. Disponível em 
$<$ www.jstor.org/stable/3243481>. Acesso em 5 maio 2015.

Delgadillo, C. 1993. The Antillean Arc and the distribution of Neotropical mosses. Trop. Bryologist 7: 7-12. Disponível em $<$ http://tropical-bryology.org/Articles/ open/VOL7/delgad.pdf $>$. Acesso em 6 maio 2015.

Dillon, M.O. 1994-2010. Andean Botanical Information System (ABIS) Webpage. Disponível em $<$ http:// www.sacha.org>. Acesso em 2 maio 2015.

Dillon, M.O. \& Rundel, P.W. 1990. The botanical response of the Atacama and Peruvian Desert Flora to the 1982-83 El Niño event. In: Glynn, P.W. Global ecological consequences of the 1982-83 El Niñosouthern oscillation. Elsevier Science Publishers, New York. Pp. 487-504.

Fahn, A. 1964. Some anatomical adaptations in desert plants. Phytomorphology 14: 93-102.

Fiaschi, P. \& Pirani, J.R. 2008. Padrões de distribuição geográfica das espécies de Schefflera J.R. Forst. \& G. Forst. (Araliaceae) do Brasil extra-amazônico. Revista Brasileira de Botânica 31: 633-644. Disponível em <http://dx.doi.org/10.1590/S010084042008000400009>. Acesso em 2 abril 2015.

Gentry,A.H. 1978. Floristic knowledge and needs in Pacific Tropical America. Brittonia 30: 134-153. Disponível em <www.jstor.org/stable/2806640>. Acesso em 2 maio 2015.

Gottsberger G. \& Silberbauer-Gottsberger, I. 2006. Life in the Cerrado, a South American tropical seasonal ecosystem. Vol 1. Origin, structure, dynamics and plant use. Reta, Verlag. 280p.

Granville, J.J. 1992. Un cas de distribution particulier: les espèces forestieres peri-amazoniennes. Compte Rendu des Séances de la Société de Biogeographie 68: 1-33.

Iturralde-Vinent, M.A. \& MacPhee, R.D.E. 1999. Paleogeography of the Caribbean region: implications for Cenozoic biogeography. Bulletin of the American Museum of Natural History 238: 1-95.

Lomolino, M.V.; Riddle, B.R. \& Brown, J.H. 2006. Biogeography. $3^{\text {rd }}$ ed. Sinauer Associates, Sunderland. $752 \mathrm{p}$.

Lopez, R.P.; Alcazár, D.L. \& Macía, M.J. 2006. The arid and dry plant formations of South America and their floristic connections: new data, new interpretation? Darwiniana 44: 18-31. Disponível em <www.redalyc. org/articulo.oa?id=66944102>. Acesso em 10 abril 2015.

Loueuille, B.; Semir, J.; Lohmann, L.G. \& Pirani, J.R. 2015.A phylogenetic analysis of Lychnophorinae (Asteraceae: Vernonieae) based on molecular and morphological data. Systematic Botany, 40: 299-315. Disponível em $<$ http://dx.doi.org/10.1600/036364415X686585>. Acesso em 15 maio 2015.

Löwenberg-Neto, P. 2014. Neotropical region: a shapefile of Morrone's (2014) biogeographical regionalization. Zootaxa 3802: 300. Disponível em <http://dx.doi. org/10.11646/zootaxa.3802.2.12>. Acesso em 10 abril 2015.
Löwenberg-Neto, P. 2015. Andean region: a shapefile of Morrone's (2015) biogeographical regionalization. Zootaxa 3985: 600. Disponível em <http://www. mapress.com/zootaxa/2015/f/z03985p600f.pdf $>$. Acesso em 2 maio 2015.

Luebert, F. \& Weigend, M. 2014. Phylogenetic insights into Andean plant diversification Frontiers in Ecology and Evolution 2: 27. Disponível em $<$ http://journal. frontiersin.org/article/10.3389/fevo.2014.00027/ full>. Acesso em 10 abril 2015.

Luteyn, J. 1999. Páramos: a checklist of plant diversity, geographical distribution, and botanical literature. Memoirs of the New Yoyk Botanical Garden 84: $278 \mathrm{p}$.

Magenta, M.A.G. 2006. Viguiera Kunth (Asteraceae, Heliantheae) na América do Sul e sistemática das espécies do Brasil. Tese de Doutorado, Universidade de São Paulo, São Paulo. 353p.

Magenta, M.A.G. \& Pirani, J.R. 2014. Novidades taxonômicas em Aldama (Asteraceae-Heliantheae). Rodriguésia 65: 175-192. Disponível em <http:// rodriguesia.jbrj.gov.br/FASCICULOS/rodrig65-1/ ID\%20687.pdf>. Acesso em 15 maio 2015. Disponível em <http://www.teses.usp.br/teses/ disponiveis/41/41132/tde-12032008-162008/pt-br. php>. Acesso em 2 maio 2015.

Magenta, M.A.G.; Pirani, J.R. \& Mondin, C.A. 2010. Novos táxons e combinações de Viguiera Kunth (Asteraceae-Heliantheae) no Brasil. Rodriguésia 61: 1-11. Disponível em <http://rodriguesia.jbrj.gov.br/ FASCICULOS/rodrig61_1/1\%20-\%20Viguiera.pdf>. Acesso em 20 maio $201 \overline{5}$.

Montúfar, R. \& Pitman, N. 2003a. Viguiera media. The IUCN red list of threatened species. Version 2014.1. Disponível em <http://dx.doi.org/10.2305/IUCN. UK.2003.RLTS.T43863A10827495.en>. Acesso em 23 maio 2015.

Montúfar, R. \& Pitman, N. 2003b. Viguiera sodiroi. The IUCN red list of threatened species. Version 2014.1. Disponível em <http://dx.doi.org/10.2305/IUCN. UK.2003.RLTS.T43864A10827717.en>. Acesso em 23 maio 2015.

Morrone, J.J. 1999. Presentación preliminar de un nuevo esquema biogeográfico de América del Sur. Biogeographica 75: 1-16. Disponível em $<$ www.sea-entomologia.org/PDF/M3 M PRIBES 2002/267 276 Morrone.pdf>. Acesso em 1 maio 2015 .

Morrone, J.J. 2001. Biogeografía de América Latina y el Caribe. Vol. 3. M \& T - manuales \& tesis SEA, Sociedad Entomológica Aragonesa, Zaragoza. 148p. Disponível em <www.sea-entomologia.org/ PDF/M\&TSEA03-1p.pdf $>$. Acesso em 23 maio 2015.

Morrone, J.J. 2004a. Panbiogeografía, componentes bióticos y zonas de transición. Revista Brasileira de Entomologia 48: 149-162. Disponível em <http:// dx.doi.org/10.1590/S0085-56262004000200001>. Acesso em 10 maio 2015. 
Morrone, J.J. 2004b. La zona de transición Sudamericana: Caracterización y relevancia evolutiva. Acta Entomologica Chilena 28: 41-50.

Morrone, J.J. 2006. Biogeographic áreas and transition zones of latin America and the caribbean islands based on pangiogeographic and cladistic analysis of entomofauna. Annual Review of Entomology 51: 467-94. Disponível em <www.annualreviews.org/ doi/full/10.1146/annurev.ento.50.071803.130447>. Acesso em 10 abril 2015.

Morrone, J.J. 2010. América do Sul e geografia da vida: Comparação de algumas propostas de regionalização. In: Carvalho, C.J.B. \& Almeida, E.A.B. Biogeografia da América do Sul: Padrões e processos. Editora Roca Limitada, São Paulo. Pp. $14-40$.

Morrone, J.J. 2014a. Cladistic biogeography of the Neotropical region: Identifying the main events in the diversification of the terrestrial biota. Cladistics 30: 202-214.

Morrone, J.J. 2014b. Biogeographical regionalisation of the Neotropical region. Zootaxa monographys 3782: 1-110. Disponível em <http://dx.doi.org/10.11646/ zootaxa.3782.1.1>. Acesso em 10 maio 2015.

Morrone, J.J. 2015. Biogeographical regionalisation of the Andean region. Zootaxa 3936: 207-336. Disponível em < http://dx.doi.org/10.11646/ zootaxa.3936.2.3>. Acesso em 10 maio 2015.

Prohaska, F. 1973. New evidence on the climatic controls along the Peruvian coast. In: Amiran, D.H.K. \& Wilson, A.W. Coastal deserts, their natural and human environments University. Arizona Press, Tucson. Pp. 91-107.

Qgis 2.6. 2014. Quantum GIS development team (YEAR). Quantum GIS geographic information system. Open source geospatial foundation project. Disponível em <http://qgis.osgeo.org/en/site/>. Acesso em 10 março 2015.

Rando, J.G. \& Pirani, J.R. 2011. Padrões de distribuição geográfica das espécies de Chamaecrista sect. Chamaecrista ser. Coriaceae (Benth.) H.S. Irwin \& Barneby, Leguminosae, Caesalpinioideae. Revista Brasileira de Botânica 34: 499-513. Disponível em <http://dx.doi.org/10.1590/S010084042011000400004>. Acesso em 8 maio 2015.

Raven P.H. \& Axelrod, D.I. 1974. Angiosperm biogeography and past continental movements. Annals of Missouri Botanical Garden 61: 539-673.

Robinson, H. \& Moore, A.J. 2004. New species and new combinations in Rhysolepis (Heliantheae Asteraceae). Proceedings of the Biological Society of Washington 117: 423-446.
Ruggiero, A. \& Ezcurra, C. 2003. Regiones y transiciones biogeográficas: Complementariedad de lós análisis en biogeografia histórica y ecológica. In: Morrone, J.J. \& Llorente, J. Una perspectiva latinoamericana de la biogeografía. Las Prensas de Ciencias, UNAM, Mexico. Pp. 141-154.

Schilling, E.E. \& Panero, J.L. 1996. Relationships in Heliantheae subtribe Helianthinae based on chloroplast DNA restriction site analysis. In: Hind, D.J. \& Beentje, H.J. Compositae: systematics proceedings of the international Compositae conference. Vol. 1. Royal Botanic Gardens, Kew. Pp. 361-376.

Schilling, E.E. \& Panero, J.L. 2002. A revised classification of subtribe Helianthinae (AsteraceaeHeliantheae) I. Basal lineages. Botanical Journal of the Linnean Society 140: 65-76.

Schilling, E.E. \& Panero, J.L. 2011. A revised classification of subtribe Helianthinae (Asteraceae: Heliantheae) II. Derived Lineages. Botanical Journal of the Linnean Society 167: 311-331.

Silva, E.M.S.; Hayashi, A.H. \& Appezzato-da-Glória, B. 2014. Anatomy of vegetative organs in Aldama tenuifolia and A. kunthiana (Asteraceae: Heliantheae). Brazilian Journal of Botany 37: 505517. Disponível em <http://dx.doi.org/10.1007/ s40415-014-0101-2>. Acesso em abril 2015.

Simon, M.F. \& Pennington T. 2012. Evidence for adaptation to fire regimes in the tropical savannas of the Brazilian Cerrado. International Journal of Plant Sciences 173: 711-723. Disponível em $<$ http:// dx.doi.org/10.1086/665973>. Acesso em abril 2015.

Stehli, F.G. \& Webb, S.D. (eds). 1985. The Great American Biotic Interchange. Plenum Press, New York. XVII + 532p.

Thiers, B. [continuamente atualizado]. Index Herbariorum: A global directory of public herbaria and associated staff. New York Botanical Garden's Virtual Herbarium. Disponível em <http:// sweetgum.nybg.org/ih>. Acesso em abril 2015.

Vijn, I. \& Smeekens, S. 1999. Fructan: more than a reserve carbohydrate? Plant Physiology 120: 351359. Disponível em <http://www.plantphysiology. org/content/120/2/351.full.pdf $>$. Acesso em abril 2015.

Weberbauer, A. 1936. Phytogeography of the Peruvian Andes. Field Museum of Natural History, Botanical series 15: 1-587.

Zucol, A.F. 2000. Pastizales sudamericanos. Cartilla de difusión de ciencias naturares 2. Centro de investigaciones científicas CICYTTP, Entre Ríos. 12p. 